\title{
Diagnostic Ureteroscopy for Upper Tract Urothelial Carcinoma is Independently Associated with Intravesical Recurrence after Radical Nephroureterectomy
}

\author{
Pei Liu ${ }^{1}$, Xiao-hong Su ${ }^{1}$, Geng-Yan Xiong ${ }^{1}$, Xue-Song Li ${ }^{1}$, Li-Qun Zhou ${ }^{1}$ \\ ${ }^{1}$ Department of Urology, Peking University First Hospital, Institute of Urology, Peking University, National \\ Urological Cancer Center, Beijing, China
}

\section{ABSTRACT}

Purpose: To determine the effect of diagnostic ureteroscopy on intravesical recurrence in patients with upper tract urothelial carcinoma (UTUC) after radical nephroureterectomy (RNU).

Materials and Methods: We conducted a retrospective analysis of 664 patients who were treated with RNU for UTUC from June 2000 to December 2011, excluding those who had concomitant/prior bladder tumors. Of the 664 patients, 81 underwent diagnostic ureteroscopy (URS). We analyzed the impact of diagnostic ureteroscopy on intravesical recurrence (IVR) using the Kaplan-Meier method. Univariate and multivariate analyses were used to determine the independent risk factors.

Results: The median follow-up time was 48 months (interquartile range (IQR): 3177 months). Patients who underwent ureteroscopy were more likely to have a small $(p<0.01)$, early-staged $(p=0.019)$, multifocality $(p=0.035)$ and ureteral tumor $(p<0.001)$. IVR occurred in 223 patients during follow-up within a median of 17 months (IQR: 7-33). Patients without preoperative ureteroscopy have a statistically significant better 2-year $(79.3 \% \pm 0.02$ versus $71.4 \% \pm 0.02, \mathrm{p}<0.001)$ and 5 -year intravesical recurrencefree survival rates $(64.9 \% \pm 0.05$ versus $44.3 \% \pm 0.06, \mathrm{p}<0.001)$ than patients who underwent ureteroscopy. In multivariate analysis, the diagnostic ureteroscopy $(p=0.006)$, multiple tumors $(\mathrm{p}=0.001)$, tumor size $<3 \mathrm{~cm}(\mathrm{p}=0.008)$, low-grade $(\mathrm{p}=0.022)$ and $\mathrm{pN}_{0}$ stage tumor $(\mathrm{p}=0.045)$ were independent predictors of IVR.

Conclusions: Diagnostic ureteroscopy is independently associated with intravesical recurrence after radical nephroureterectomy.

\section{ARTICLE INFO}

\section{Keywords:}

Ureteroscopy; Oncology; Bladder; Ureter; Urinary Tract

Int Braz J Urol. 2016; 42: 1129-35

Submitted for publication: July 09, 2015

\section{Accepted after revision:}

February 29, 2016

Published as Ahead of Print:

August 17, 2016

\section{INTRODUCTION}

Upper tract urothelial carcinoma (UTUC) is rare and accounts for only 5-10\% of urothelial carcinoma cases, with an annual incidence of 1-2 cases per 100.000 in Western countries (1-3). Radical nephroureterectomy (RNU) with bladder cuff excision is the gold standard for managing UTUC
(4). The incidence of subsequent intravesical recurrence (IVR) following RNU is 22-47\%, which means a close follow-up using cystoscopy is required to detect the high incidence of $\operatorname{IVR}(5,6)$.

Several risk factors are reported to be associated with IVR, such as the age, sex, tumor location, multiplicity, size, surgical approach (open or laparoscopic surgery) and distal ureter 
management, T stage, grade, carcinoma in situ, and history of bladder cancer (7). With the development of medical devices, diagnostic ureteroscopy is becoming a powerful tool for patients with UTUC, which could contribute to the diagnostic certainty and decision making regarding treatment options. The European guidelines suggest that diagnostic ureteroscopy should be performed in the preoperative assessment of any UTUC patient (Grade C) (8). Concerns, however, have been raised that there is a possible risk of tumor implantation during ureteroscope manipulation and irrigation (9).

To the best of our knowledge, previous studies are sparse, and there is no consistent conclusion on the impact of diagnostic ureteroscopy for intravesical recurrence (9-11). Therefore, we conducted this study, based on data from a large center in China, to determine whether diagnostic ureteroscopy results in IVR after RNU.

\section{MATERIALS AND METHODS}

The follow-up data of patients with UTUC who were treated with RNU at Peking University First Hospital, Beijing, China, from June 2000 to December 2011 were reviewed. Out of 892 patients submitted to RNU in our service we selected 753 with complete FU information. Among these 753 patients, we excluded 82 patients with concomitant/prior bladder tumors, 6 patients with bilateral UTUC, and 1 patient with distant metastasis. Therefore, 664 patients were included in this study. None of these patients received neoadjuvant or adjuvant chemotherapy.

Of 664 patients, 583 in the control group were diagnosed by CT/MRI, urinary cytology specimens and retrograde pyelography. Eighty-one patients underwent diagnostic ureteroscopy and were included in the study group. Diagnostic ureteroscopy is especially used when there is diagnostic uncertainty or when conservative treatment is being considered, but there are no standardized prospective criteria. Chest X-ray and preoperative cystoscopy were performed in all patients to rule out metastasis and concomitant bladder tumors.

All patients underwent retroperitoneal open or laparoscopic nephroureterectomy. In all cases, the ureter was ligated immediately af- ter control of the renal artery without dissecting around the kidney. The distal ureter and bladder cuff were all managed by extravesical dissection and the intramural portion within the bladder wall through an open Gibson incision. A regional lymph node dissection was performed in case of suspicious lymph node invasion on preoperative imaging or intraoperative examination.

The clinicopathologic data were retrospectively recorded. All tumors were graded by the World Health Organization classification of 2004 and staged by the Union for International Cancer Control TNM classification of malignant tumors 2002. The tumor location was defined as renal pelvis or ureter, and tumor multifocality was defined as the presence of two or more macroscopic tumors in the upper urinary tract.

During follow-up, patients received cystoscopy every 3 months for the first 2 years, which extended to 1 year thereafter. Serum creatinine level, chest X-ray and CT or MRI were performed simultaneously.

All statistical data were managed with SPSS version 19.0. Statistical significance was set at $p<0.05$. Continuous variables were compared using the two-sample t-test, and categorical variables were compared using the Chi square test. The Kaplan-Meier method was used to estimate the survival outcomes. Univariate analysis with the log-rank test and multivariate analysis with Cox proportional hazards regression model were used. Only variables that were significant according to univariate analysis were considered for the multivariate analysis.

\section{RESULTS}

The clinicopathologic features are summarized in Table- 1 . The median patient age was 68 years (IQR: 60-74 months). The median follow-up time was 48 months (IQR: 31-77 months). There was no significant difference in gender, age, smoking status, surgical mode, presence of hydronephrosis, presence of carcinoma in situ, $\mathrm{N}$ stage or tumor grade. Patients who underwent ureteroscopy were more likely to have a small $(p<0.01)$, early-staged $(p=0.019)$, multifocality $(p=0.035)$ and ureteral tumor $(\mathrm{p}<0.001)$. 
Table 1 - Clinicopathological characteristics of 664 patients with RNU for UTUC.

\begin{tabular}{|c|c|c|c|}
\hline & $\begin{array}{c}\text { URS }(+) \\
n=81\end{array}$ & $\begin{array}{l}\text { URS(-) } \\
n=583\end{array}$ & $p$ values \\
\hline \multicolumn{4}{|l|}{ Gender } \\
\hline Male & $31(38.3 \%)$ & $264(45.3 \%)$ & \multirow{2}{*}{0.234} \\
\hline Female & $50(61.7 \%)$ & $319(54.7 \%)$ & \\
\hline Age (years) & $65.9 \pm 11.3$ & $66.6 \pm 10.7$ & 0.617 \\
\hline \multicolumn{4}{|l|}{ Smoking } \\
\hline yes & $10(12.3 \%)$ & $111(19.0 \%)$ & \multirow{2}{*}{0.144} \\
\hline no & $71(87.7 \%)$ & $472(81.0 \%)$ & \\
\hline \multicolumn{4}{|l|}{ Surgical mode } \\
\hline Laparoscopic & $23(28.4 \%)$ & $196(33.6 \%)$ & \multirow{2}{*}{0.349} \\
\hline Open & $58(71.6 \%)$ & $387(66.4 \%)$ & \\
\hline \multicolumn{4}{|l|}{ Tumor location } \\
\hline Pelvis & $26(32.1 \%)$ & $342(58.7 \%)$ & \multirow{2}{*}{$P<0.001^{*}$} \\
\hline Ureter & $55(67.9 \%)$ & $241(41.3 \%)$ & \\
\hline \multicolumn{4}{|l|}{ Multifocality } \\
\hline Multiple & $27(33.3 \%)$ & $132(22.6 \%)$ & \multirow{2}{*}{$0.035^{\star}$} \\
\hline Solitary & $54(66.7 \%)$ & $451(77.4 \%)$ & \\
\hline \multicolumn{4}{|l|}{ Hydronephrosis } \\
\hline present & $45(55.6 \%)$ & $329(56.4 \%)$ & \multirow{2}{*}{0.882} \\
\hline absent & $36(44.4 \%)$ & $254(43.6 \%)$ & \\
\hline \multicolumn{4}{|l|}{ Tumor size } \\
\hline$\geq 3 \mathrm{~cm}$ & $28(34.6 \%)$ & $335(57.5 \%)$ & \multirow{2}{*}{$P<0.001^{*}$} \\
\hline$<3 \mathrm{~cm}$ & $53(65.4 \%)$ & $248(42.5 \%)$ & \\
\hline \multicolumn{4}{|l|}{ Cis } \\
\hline present & $4(4.9 \%)$ & $15(2.6 \%)$ & \multirow{2}{*}{0.400} \\
\hline absent & $77(95.1 \%)$ & $568(97.4 \%)$ & \\
\hline \multicolumn{4}{|l|}{ pT stage } \\
\hline$\leq \mathrm{T} 2$ & $65(80.2 \%)$ & $393(67.4 \%)$ & \multirow{2}{*}{$0.019^{*}$} \\
\hline$>\mathrm{T} 2$ & $16(19.8 \%)$ & $190(32.6 \%)$ & \\
\hline \multicolumn{4}{|l|}{ N stage } \\
\hline $\mathrm{N}_{+}$ & $3(3.7 \%)$ & $44(7.5 \%)$ & \multirow{2}{*}{0.206} \\
\hline NO & $78(96.3 \%)$ & $539(92.5 \%)$ & \\
\hline \multicolumn{4}{|l|}{ Tumor grade } \\
\hline Low & $51(63.0 \%)$ & $330(56.6 \%)$ & \multirow{2}{*}{0.278} \\
\hline High & $30(37.0 \%)$ & $253(43.4 \%)$ & \\
\hline
\end{tabular}

${ }^{*} p<0.05$, significant difference was reached 
There was intravesical recurrence in 223 patients (33.6\%) during follow-up within a median of 17 months (IQR: 7-33 months). The 2-year and 5-year intravesical recurrence-free survival rates for patients with and without ureteroscopy were $71.4 \% \pm 0.02$ versus $79.3 \% \pm 0.02$ and $44.3 \% \pm 0.06$ versus 64.9\% \pm 0.05 , respectively (Figure-1).

In univariate analysis, diagnostic ureteroscopy and tumor multifocality, tumor size, tumor location, T stage, $\mathrm{N}$ stage and grade were all associated with intravesical recurrence while in multivariate Cox regression analysis only the diagnostic ureteroscopy $(p=0.006)$, multiple tumors $(\mathrm{p}=0.001)$, tumor size $<3 \mathrm{~cm}(\mathrm{p}=0.008)$, low-grade tumor $(\mathrm{p}=0.022)$ and $\mathrm{pN}_{0}$ stage $(\mathrm{p}=0.045)$ were independent predictors (Table-2).

\section{DISCUSSION}

RNU with bladder cuff excision is the gold standard for managing UTUC (4). However, a high potential of intravesical recurrence after RNU has been reported. In the guidelines for NCCN, all UTUC patients after RNU are recommended to undergo cystoscopy for routine bladder surveillance (12). In this retrospective study, the incidence of IVR was $33.6 \%$, which is in agreement with previous reports $(22-47 \%)(5,6)$. The explanation of such a high incidence of IVR can only be hypothesized, including the field cancerization hypothesis and intraluminal seeding of the tumor $(13,14)$.

Several studies have evaluated the risk factors for IVR after RNU, such as age, gender, tumor multiplicity, TNM stage, grade, tumor location, size, previous/concomitant bladder tumors, carcinoma in situ, surgical mode and distal ureter management (7, 15-22). Among these factors, a history of a prior bladder tumor and a multifocal primary tumor are the most frequently reported, while others are still under debate. In the present study, however, we excluded the patients with previous/concomitant bladder cancer because the incidence of IVR in those patients is related to local disease instead of UTUC or ureteroscopic

Figure 1 - Kaplan-Meier survival curves for intravesical recurrence-free survival stratified by preoperative diagnostic ureteroscopy.

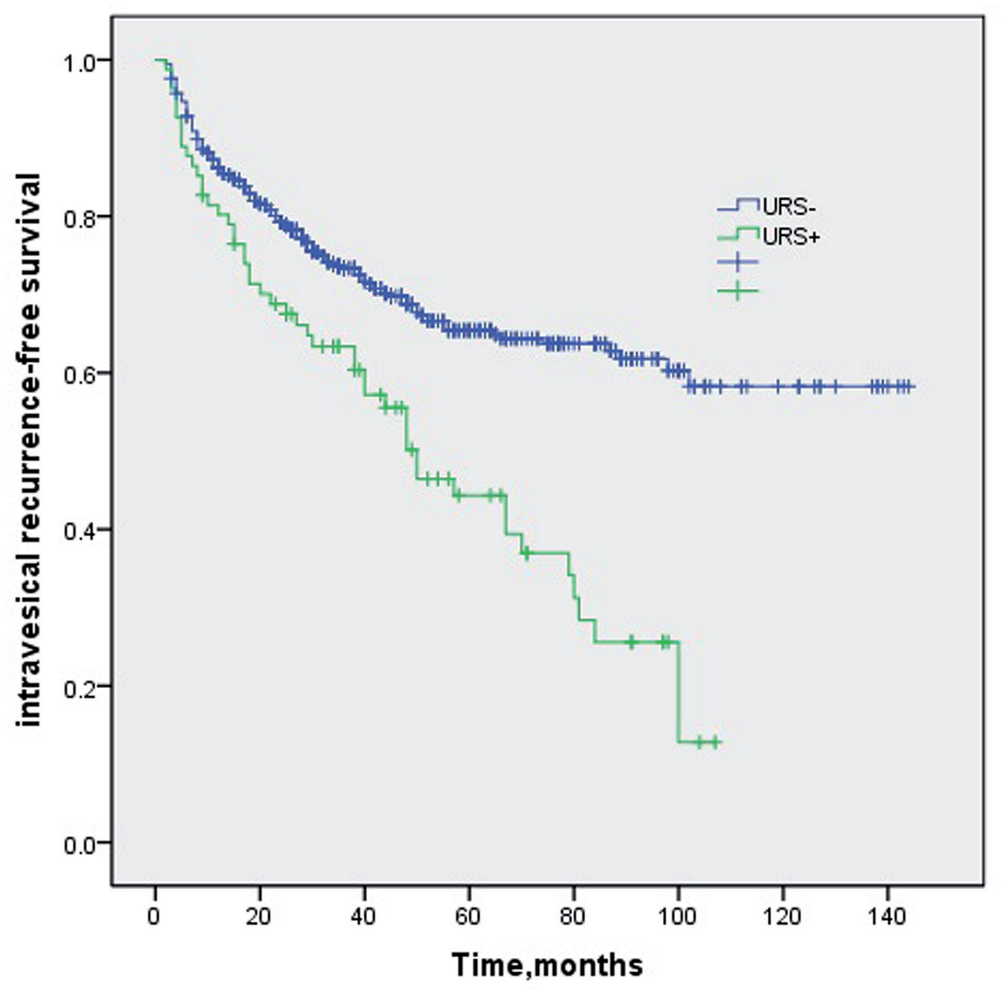


Table 2 - Univariable and multivariate Cox regression analyses predicting intravesical recurrence in 664 patients after nephroureterectomy for UTUC.

\begin{tabular}{|c|c|c|c|c|}
\hline & \multirow[t]{2}{*}{ Univariate analysis ( $\mathrm{P}$ value) } & \multicolumn{3}{|c|}{ Multivariate Cox Regression analysis } \\
\hline & & $H R$ & $95 \% \mathrm{Cl}$ & $P$ \\
\hline Diagnostic ureteroscopy & $<0.001$ & 1.592 & $1.143-2.218$ & $0.006^{*}$ \\
\hline Multifocal tumor & $<0.001$ & 1.596 & $1.206-2.111$ & $0.001^{*}$ \\
\hline Tumor size $<3 \mathrm{~cm}$ & $<0.001$ & 1.459 & $1.104-1.929$ & $0.008^{*}$ \\
\hline Low-grade tumor & 0.001 & 1.438 & $1.053-1.964$ & $0.022^{*}$ \\
\hline $\mathrm{pN}_{0}$ stage & 0.004 & 2.512 & $1.019-6.195$ & $0.045^{*}$ \\
\hline Tumor located in ureter & 0.01 & 1.295 & $0.984-1.705$ & 0.065 \\
\hline $\mathrm{pT}$ stage $\leq \mathrm{T}_{2}$ & 0.023 & 0.907 & $0.639-1.287$ & 0.982 \\
\hline Age more than 70 & 0.737 & & & \\
\hline $\begin{array}{l}\text { Presence of } \\
\text { hydronephrosis }\end{array}$ & 0.065 & & & \\
\hline Smoking & 0.934 & & & \\
\hline Laparoscopic surgery & 0.871 & & & \\
\hline Female & 0.293 & & & \\
\hline Presence of Cis & 0.606 & & & \\
\hline
\end{tabular}

${ }^{*} \mathrm{p}<0.05$, significant difference was reached

procedure. The presence of multiple tumors remains the predictive factor for IVR when patients with a history of bladder cancer are excluded. Additionally, low-grade tumors, $\mathrm{pN}_{0}$ stage and tumor size $<3 \mathrm{~cm}$ are associated with IVR. In our previous study (7), the influence of tumor grade on bladder recurrence was not that significant when excluding the patients that died during follow-up without bladder recurrence $(p=0.061)$. Thus, we consider this result may be attributed to the fact that high-grade, $\mathrm{N}_{+}$patients or those with large tumors may suffer from tumor dissemination and die prior to the detection of IVR.

With the development of medical devices, diagnostic ureteroscopy is becoming a powerful tool for patients with UTUC, and it is used to visualize and biopsy the entire upper urinary tract with a technical success approaching 95\% (23). Coupled with biopsies, it provides satisfactory diagnostic accuracy (24). However, concerns have been raised that tumor implantation may result from ureteroscope manipulation and irrigation. Retrograde flow, increased urine flow rate and intraluminal pressure might lead to the shedding of tumor cells, which implant in the bladder to develop recurrences. There are only 3 previous studies on the impact of diagnostic ureteroscopy for IVR after RNU, and they do not reach a consistent conclusion (9-11). Nison et al. reported that there was intravesical recurrence 146 times, which was $28 \%$ in the URS group and $27.5 \%$ in the URS+group (not significantly different). In addition, they did not find that ureteroscopy is an independent risk factor for IVR (9). Ishikawa et al. reached the same conclusion as Nison, and the 2-year bladder recurrence-free survival rate was $60.0 \%$ in their URS+group and 58.7\% in their control group (10). Luo et al., by contrast, reported that ureteroscopy was associated with an increased incidence of intravesical recurrence in patients with or without a history of bladder cancer (11). In the present stu$\mathrm{dy}$, it is possible that diagnostic ureteroscopy is an 
independent predictive factor for IVR, providing evidence for the intraluminal seeding hypothesis.

The question remains whether we should use diagnostic ureteroscopy as a routine preoperative examination. The European guidelines suggest that diagnostic ureteroscopy should be performed in the preoperative assessment of any UTUC patient (8). However, diagnostic ureteroscopy may have the potential risk of future intravesical recurrence by increasing tumor cell shedding during manipulation and irrigation. We should find a balance between misdiagnosis without preoperative URS, which may result in unnecessary nephrectomy, and the potential risk of IVR after RNU.

There are several limitations of this study, including the retrospective design and data collection, which may lead to selection and recall bias. No strict criteria for preoperative ureteroscopy were established, and each surgeon independently made the decision to perform URS. In spite of these limitations, our study is still the largest single-center study in China on IVR after RNU for patients without a history of bladder cancer. Further molecular genetic studies and randomized control trials are needed to help determine the mechanism for intravesical recurrence.

\section{CONCLUSIONS}

Diagnostic ureteroscopy is independently associated with intravesical recurrence after radical nephroureterectomy. Urologists should reconsider the use of diagnostic ureteroscopy as a routine preoperative assessment. We should find a balance between misdiagnosis without preoperative URS, which may result in unnecessary nephrectomy, and the potential risk of IVR after RNU.

\section{ABBREVIATIONS}

UTUC = Upper tract urothelial carcinoma

RNU = Radical nephroureterectomy

IVR = intravesical recurrence

\section{ACKNOWLEDGEMENTS}

Pei Liu, Xiao-hong Su

These authors contribute equally

\section{CONFLICT OF INTEREST}

None declared.

\section{REFERENCES}

1. Munoz JJ, Ellison LM. Upper tract urothelial neoplasms: incidence and survival during the last 2 decades. J Urol. 2000;164:1523-5.

2. Siegel R, Naishadham D, Jemal A. Cancer statistics, 2012. CA Cancer J Clin. 2012;62:10-29.

3. Cosentino M, Palou J, Gaya JM, Breda A, Rodriguez-Faba O, Villavicencio-Mavrich $\mathrm{H}$. Upper urinary tract urothelial cell carcinoma: location as a predictive factor for concomitant bladder carcinoma. World J Urol. 2013;31:141-5.

4. Rouprêt M, Babjuk M, Compérat E, Zigeuner R, Sylvester RJ, Burger M, et al. European Association of Urology Guidelines on Upper Urinary Tract Urothelial Cell Carcinoma: 2015 Eur Urol. 2015;68:868-79.

5. Zigeuner RE, Hutterer G, Chromecki T, Rehak P, Langner C. Bladder tumour development after urothelial carcinoma of the upper urinary tract is related to primary tumour location. BJU Int. 2006;98:1181-6.

6. Novara G, De Marco V, Dalpiaz 0, Gottardo F, Bouygues V, Galfano A, et al. Independent predictors of metachronous bladder transitional cell carcinoma (TCC) after nephroureterectomy for TCC of the upper urinary tract. BJU Int. 2008;101:1368-74.

7. Fang D, Xiong GY, Li XS, Chen XP, Zhang L, Yao L, et al. Pattern and risk factors of intravesical recurrence after nephroureterectomy for upper tract urothelial carcinoma: a large Chinese center experience. J Formos Med Assoc. 2014;113:820-7.

8. Rouprêt M, Babjuk M, Compérat E, Zigeuner R, Sylvester R, Burger $\mathrm{M}$, et al. European guidelines on upper tract urothelial carcinomas: 2013 update. Eur Urol. 2013;63:1059-71.

9. Luo HL, Kang CH, Chen YT, Chuang YC, Lee WC, Cheng YT, et al. Diagnostic ureteroscopy independently correlates with intravesical recurrence after nephroureterectomy for upper urinary tract urothelial carcinoma. Ann Surg Oncol. 2013;20:3121-6. 
10. Ishikawa S, Abe T, Shinohara N, Harabayashi T, Sazawa A, Maruyama S, et al. Impact of diagnostic ureteroscopy on intravesical recurrence and survival in patients with urothelial carcinoma of the upper urinary tract. J Urol. 2010;184:883-7.

11. Nison L, Rouprêt M, Bozzini G, Ouzzane A, Audenet F, Pignot $G$, et al. The oncologic impact of a delay between diagnosis and radical nephroureterectomy due to diagnostic ureteroscopy in upper urinary tract urothelial carcinomas: results from a large collaborative database. World J Urol. 2013:31:69-76.

12. Ishioka J, Saito K, Kijima T, Nakanishi Y, Yoshida S, Yokoyama M, et al. Risk stratification for bladder recurrence of upper urinary tract urothelial carcinoma after radical nephroureterectomy. BJU Int. 2015;115:705-12.

13. Miyake H, Hara I, Kamidono S, Eto H. Multifocal transitional cell carcinoma of the bladder and upper urinary tract: molecular screening of clonal origin by characterizing CD44 alternative splicing patterns. J Urol. 2004;172:1127-9.

14. Catto JW, Hartmann A, Stoehr R, Bolderson E, Rehman I, Rosario DJ, et al. Multifocal urothelial cancers with the mutator phenotype are of monoclonal origin and require panurothelial treatment for tumor clearance. J Urol. 2006;175:2323-30.

15. Matsui Y, Utsunomiya N, Ichioka K, Ueda N, Yoshimura K, Terai $A$, et al. Risk factors for subsequent development of bladder cancer after primary transitional cell carcinoma of the upper urinary tract. Urology. 2005;65:279-83.

16. Favaretto RL, Shariat SF, Chade DC, Godoy G, Adamy A, Kaag $M$, et al. effect of tumor location on prognosis in patients treated with radical nephroureterectomy at Memorial SloanKettering Cancer Center. Eur Urol. 2010;58:574-80.

17. Lughezzani G, Sun M, Perrotte P, Shariat SF, Jeldres C, Budäus L, et al. Gender-related differences in patients with stage I to III upper tract urothelial carcinoma: results from the Surveillance, Epidemiology, and End Results database. Urology. 2010;75:321-7.

18. Xylinas E, Rink M, Cha EK, Clozel T, Lee RK, Fajkovic H, et al. Impact of distal ureter management on oncologic outcomes following radical nephroureterectomy for upper tract urothelial carcinoma. Eur Urol. 2014;65:210-7.
19. Shariat SF, Godoy G, Lotan Y, Droller M, Karakiewicz $\mathrm{PI}$, Raman JD, et al. Advanced patient age is associated with inferior cancer-specific survival after radical nephroureterectomy. BJU Int. 2010;105:1672-7. Erratum in: BJU Int. 2015;115:E13.

20. Novara G, Matsumoto K, Kassouf W, Walton TJ, Fritsche HM, Bastian PJ, et al. Prognostic role of lymphovascular invasion in patients with urothelial carcinoma of the upper urinary tract: an international validation study. Eur Urol. 2010;57:1064-71.

21. Yuan H, Chen X, Liu L, Yang L, Pu C, Li J, et al. Risk factors for intravesical recurrence after radical nephroureterectomy for upper tract urothelial carcinoma: a meta-analysis. Urol Oncol. 2014;32:989-1002.

22. Chen XP, Xiong GY, Li XS, Matin SF, Garcia M, Fang D, et al. Predictive factors for worse pathological outcomes of upper tract urothelial carcinoma: experience from a nationwide high-volume centre in China. BJU Int. 2013;112:917-24.

23. Rojas CP, Castle SM, Llanos CA, Santos Cortes JA, Bird V, Rodriguez $\mathrm{S}$, et al. Low biopsy volume in ureteroscopy does not affect tumor biopsy grading in upper tract urothelial carcinoma. Urol Oncol. 2013;31:1696-700.

24. Razavi SA, Sadigh G, Kelly AM, Cronin P. Comparative effectiveness of imaging modalities for the diagnosis of upper and lower urinary tract malignancy: a critically appraised topic. Acad Radiol. 2012;19:1134-40. 